\title{
2021, cambios y transformaciones en SUMMA
}

El año 2020 estuvo cargado de diversas dificultades a nivel mundial desde el punto de vista económico y social. La pandemia por COVID-19 indudablemente marca un antes y un después en la historia moderna de la humanidad por lo que resulta imperativo estar a la altura de estos cambios para poder darle consecución, en el caso que nos ocupa, al apoyo a la difusión de la investigación científica.

En este contexto, muchos procesos relacionados a la gestión editorial se vieron afectados presentando, entre otras cosas, atrasos en la disponibilidad y acceso web de los artículos. Si a esto se le suma la periodicidad irrestricta que deben cumplir las publicaciones periódicas, entonces el problema se puede volver mayor.

A razón de eso, y con la firme intención de ofrecer respuestas dentro del menor tiempo posible a nuestros autores, a partir del año 2021 SUMMA. Revista disciplinaria en ciencias económicas y sociales mantendrá su periodicidad bajo un formato de publicación continua, procurando así acortar los tiempos entre recepción y publicación de los artículos con el fin de que la información pueda estar oportunamente en manos de nuestros fieles lectores permitiendo de esta manera disponer de las respuestas y soluciones a los problemas de nuestro entorno de una manera efectiva.

Como es nuestra costumbre, reiteramos que SUMMA. Revista disciplinaria en ciencias económicas y sociales sigue siendo una ventana a su disposición para la publicación de sus trabajos. ¡Mucha salud para todos!

MSc. Josnel Martínez Garcés

Editor en Jefe summa@aunarcali.edu.co 